\title{
The effects of plant resource inputs on the energy flux of soil nematodes are affected by climate and plant resource type
}

Lina Zhao', Binbin Yu ${ }^{1}$, Mengmeng Wang', Jie Zhang ${ }^{1}$, Zhifeng Shen ${ }^{1}$, Yang Cui ${ }^{1}$, Junyong $\mathrm{Li}^{1}, \mathrm{Ji} \mathrm{Ye}^{2}$, Weizhong $\mathrm{Zu}^{3}$, Xiaojing Liu ${ }^{4}$, Zongji Fan ${ }^{5}$, Shenglei $\mathrm{Fu}^{1}$, Yuanhu Shao ${ }^{1, *}$

1 Laboratory of Geospatial Technology for the Middle and Lower Yellow River Regions, Ministry of Education, College of Environment and Planning, Henan University, Kaifeng 475004, China

2 CAS Key Laboratory of Forest Ecology and Management, Institute of Applied Ecology, Chinese Academy of Sciences, Shenyang 110164, China

3 Changbai Mountain Nature Conservation Management Center, Yanbian 133613, China

4 Baotianman National Nature Reserve Administrative Bureau, Nanyang 474350, China

5 Administration of Dinghushan National Nature Reserve, South China Botanical Garden, Chinese Academy of Sciences, Zhaoqing 526070 , China

H I G H L I G H T S

- We experimentally reduced litter and root inputs in forests at different latitudes.

- Litter reduction at high and mid latitudes and root removal at low latitudes reduced nematode richness but did not alter nematode abundance.

- The effects of plant resource inputs on nematode energy flux are affected by climate and plant resource type.

\section{ARTICLE INFO}

Article history:

Received December 18, 2020

Revised January 25, 2021

Accepted February 7, 2021

Keywords:

Soil nematodes

Leaf litter

Root

Energy flux

Diversity

Trophic groups

Climate

Plant-soil interactions

Soil food web
GRAPHICAL ABSTRACT

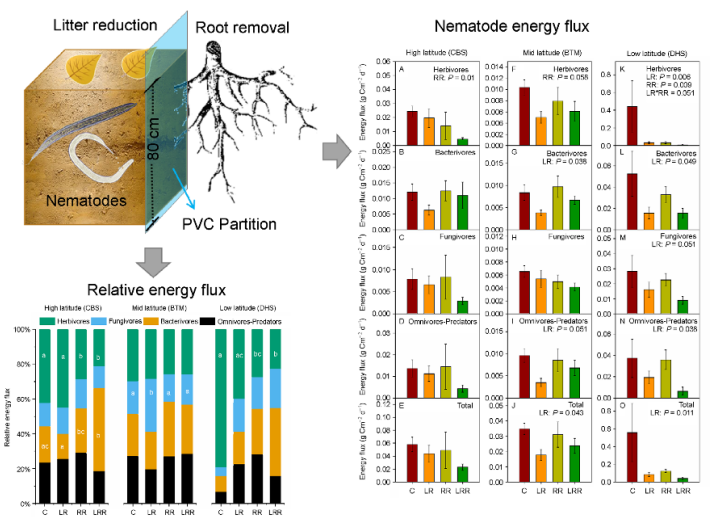

A B S T R A C T

The relative abundance of different components of the soil food web can vary tremendously in response to plant resource inputs. However, little is known about the mechanisms that plant resource regulates the energy fluxes and soil community composition. Here, we experimentally reduced litter and root inputs for two years in China at low-, mid-, and high-latitude forests to explore the effects of plant-derived resource inputs on the nematode energy flux and community composition. Litter reduction at high and mid latitudes and root removal at low latitudes reduced nematode richness but did not alter nematode abundance. Besides, litter reduction reduced energy fluxes of bacterialfeeding nematodes at mid latitudes and energy fluxes of plant-feeding, bacterial-feeding and omnivorous-predatory nematodes at low latitudes, thus reducing the energy fluxes of total nematodes in mid- and low-latitude forests. By contrast, root removal reduced energy fluxes and relative energy flux of plant-feeding nematodes in high- and low-latitude forests. In most cases, nematode diversity in different trophic groups increased with increasing energy flux to nematodes. Taken together, our results suggest that the effects of plant resource inputs on nematode energy flux are affected by climate and plant resource type, which improves our understanding of plant-soil interactions.

\footnotetext{
* Corresponding author

E-mail address: yshao@vip.henu.edu.cn (Y. Shao)
} 


\section{Introduction}

Plant-soil interactions are important for soil biodiversity and corresponding structure and function of terrestrial communities (Wardle, 2006). As resources, plants (litter, dead roots, and root exudates) can provide energy and nutrients for different components of soil food webs and influence the soil food web structure through bottom-up effects (Pollierer et al., 2007; Wardle, 2010; Pausch et al., 2016). For instance, previous studies showed that organisms in soil food webs use decaying plant detritus as energy sources (Elfstrand et al., 2008) and the planting of shrubs increases the energy flux of soil nematodes in soil food webs (Shao et al., 2019). In addition, litter removal reduced the biomass of soil fungi (Nadelhoffer et al., 2004). Plants can fuel soil food webs by determining the quantity and quality of basal resources i.e., rhizodeposits and litter (Coleman et al., 2004; Pollierer et al., 2007; Scheunemann et al., 2015). Plant-derived litter, dead roots, and root exudates are closely related to food acquisition and resource utilization of soil organisms (Högberg et al., 2001; Colloff, 2004; Wardle, 2010). The different groups of the soil food web can vary tremendously in response to resource inputs because the quantity and quality of resources can exert important effects on different groups of decomposer communities (Wardle, 2005; 2006). Such changes in soil community composition may alter soil biodiversity, predator-prey interactions, and corresponding energy fluxes in soil food webs (Schwarz et al., 2017). Thus, exploring the energy fluxes through soil food webs can help generate a better mechanistic understanding of the regulating forces of soil biodiversity. In general, litter decomposition rates are slower in high latitudes relative to low latitudes (Meentemeyer, 1978) and root turnover rates are greater at low latitudes than at high latitudes (Gill and Jackson, 2000). Thus, plant-derived litter, dead roots, and root exudates could exert different effects on soil organisms at different latitudes. However, the effects of plant-derived carbon input (litter and root) on the energy flux of the soil food web, especially at different latitudes, have not yet been explored.

The soil harbors a huge fraction of the biodiversity and multitrophic interactions, which are extraordinarily complex (Bardgett and Wardle, 2010; Bardgett and van der Putten, 2014). Nematodes comprise $80 \%$ of all multicellular animals and are a highly diverse invertebrate group (Bongers and Ferris, 1999; Hugot et al., 2001). Additionally, a recent global analysis suggested that nematode biomass is equivalent to $82 \%$ of total human biomass on Earth and the amount of carbon respired by soil nematodes is equivalent to roughly $15 \%$ of carbon emissions from fossil fuel use, or around $2.2 \%$ of the total carbon emissions from soils (van den Hoogen et al., 2019). Soil nematodes are ubiquitous and play a major role in decomposition, nutrient transformation, and energy transfer (Freckman, 1988; Bongers and Ferris, 1999; Yeates and Bongers, 1999; Neher, 2001; Coleman et al., 2004). A recent review paper suggests that nematodes can affect natural plant performance by contributing to negative plantsoil feedbacks, altering rhizosphere microbial communities, and enhancing nutrient cycling (Wilschut and Geisen, 2020). The features of soil nematodes and plant-soil interactions offer great potential for assessing the impacts of variations in plant-derived resource inputs on soil biodiversity and energy flux in soil food webs.

An effective way of studying the effects of plant-derived carbon input on soil organisms is by conducting manipulative field experiments to regulate the input of aboveground and underground organic matter (Bowden et al., 1993; Wardle et al., 2004; Yu et al., 2017). Here, we explored the effects of variations in plant-derived resource inputs on soil biodiversity and energy flux in soil food webs based on the manipulative field experiments, including litter reduction and tree root removal treatments in three typical forest ecosystems at different latitudes. Considering the basal resources of soil organisms are provided by plant litter and root exudates (Coleman et al. 2004), and the slower litter decomposition rates at high latitudes (Meentemeyer, 1978) and faster root turnover rates at low latitudes (Gill and Jackson, 2000), we hypothesized that litter reduction and/or root removal decreases total input and changes the composition of the carbohydrates in soil and subsequently decreases the energy flux, abundance and diversity of soil nematodes, and that these effects are affected by climate and plant resource type.

\section{Materials and methods}

\subsection{Site description}

To study the effects of variations in plant-derived resource inputs on nematode energy flux, we conducted manipulative field experiments, including litter reduction and tree root removal treatments in three typical forest ecosystems at different latitudes. Specifically, we selected three national nature reserves in China: Changbaishan in Jilin Province (CBS: high latitude; $42^{\circ} 24^{\prime} N$ ), Baotianman in Henan Province (BTM: mid latitude; $33^{\circ} 36^{\prime} \mathrm{N}$ ), and Dinghushan in Guangdong Province (DHS: low latitude; $23^{\circ} 10^{\prime} \mathrm{N}$ ). Litter reduction and tree root removal treatments were conducted between October and November 2016. The predominant soil types were Mollisol (dark brown soil) according to Soil Survey Staff (1999), with $56.5 \pm 5.6 \%$ clay, $32.00 \pm 3.20 \%$ silt, and $11.50 \pm$ $0.11 \%$ sand content (Qu et al., 2020); Haplic Luvisol (brown soil), with $27 \%-30 \%$ clay, $11 \%-13 \%$ silt, and $57 \%-62 \%$ sand content (Lu et al., 2017); and Haplic Ferralsol (lateritic red soil), with $17.8 \%$ clay, $61.3 \%$ silt, and $18.7 \%$ sand content (Zhang, 2011) in CBS, BTM, and DHS, respectively. The annual mean temperatures were $3.6^{\circ} \mathrm{C}, 15.1^{\circ} \mathrm{C}$, and $21.0^{\circ} \mathrm{C}$, and the annual mean precipitation was $695 \mathrm{~mm}, 885.6 \mathrm{~mm}$, and $1929 \mathrm{~mm}$ in CBS, BTM, and DHS, respectively. The detailed information on soil physical and chemical properties for each site at the initiation of the experiment is illustrated in Table 1 and the information on plant community for each site at the initiation of the experiment is illustrated in Table 2. 


\subsection{Experimental design}

The experiment was designed as a randomized complete block design with four blocks in each nature reserve. Four treatments were assigned randomly to four plots within each block. Specifically, two $100 \mathrm{~m}^{2}(10 \mathrm{~m} \times 10 \mathrm{~m})$ plots (one for control without treatment and another for the litter reduction treatment) and two $3 \mathrm{~m}^{2}(1.5 \mathrm{~m} \times 2 \mathrm{~m}$ ) plots (one for the root removal treatment and another for the litter reduction plus root removal treatment) were established. For the root removal treatment, in order to exclude the disturbances from the roots outside the plots, the plot perimeters were trenched to a depth of $80 \mathrm{~cm}$. For the litter reduction treatment, leaf litter was removed periodically to prevent it from accumulating on the soil surface.

\subsection{Soil sampling and analyses}

Soil sampling was conducted between October and November 2018, that is, two years after the treatment application. Five soil cores (5 cm diameter and $10 \mathrm{~cm}$ depth) were collected and combined into a single composite sample in plots for control without treatment (C) and another for litter reduction treatment (LR). Three soil cores $(5 \mathrm{~cm}$ diameter and $10 \mathrm{~cm}$ depth) were collected and combined into a single composite sample in plots of the root removal treatment (RR) and another for the litter reduction plus root removal treatment $(\mathrm{LRR})$. As a result, 48 samples (three sites $\times$ four treatments $\times$ four replicate blocks) were taken. Litter was removed from the soil surface before soil samples were taken. Visible roots in the soil samples were removed by hand as soon as possible. The soil cores from each plot were used for nematode energy flux, abundance and diversity indices.

Nematodes were extracted from $50 \mathrm{~g}$ of fresh soil using Baermann funnels for each composite soil sample (Barker, 1985). After fixation in $4 \%$ formalin solution, nematodes were counted under an inverted microscope, and the first 100 individuals encountered were identified to genus or family level and classified into trophic groups (plant-feeding nematodes, bacterial-feeding nematodes, fungal-feeding nematodes, omnivorous-predatory nematodes) (Yeates et al., 1993). All nematodes were identified when the nematode number was lower than 100 individuals in a sample. The total biomass (wet mass) was estimated using the mean biomass of nematode genera based on the body width of nematodes (Zhao et al., 2019).

Nematode biomass $\mathrm{C}$ was calculated by multiplying the abundance of each taxon by their calculated fresh weight, and then it was converted assuming that $25 \%$ of the wet weight is the dry weight of the nematodes (Yeates, 1979) and that the $C$ content is $50 \%$ of the dry weight (Holtkamp et al., 2008). Nematode numbers were related to grams of soil (d.w.) and subsequently transformed to densities per $\mathrm{m}^{2}$ by using soil bulk density data. On the basis of the densities per $\mathrm{m}^{2}$ and mean $\mathrm{C}$ dry masses, we estimated the biomass of the four nematode feeding guilds per $\mathrm{m}^{2}$. Calculation of nematode metabolic rates and energy fluxes was based on the methods described by Ehnes et al. (2011), Barnes et al. (2014), and Schwarz et al. (2017). More specifically, we calculated mean metabolic rates for each identified nematode taxon using

Table 1 Soil moisture (SM), soil organic carbon (SOC), total soil nitrogen (TSN), total soil phosphorus (TSP), available soil phosphorus (ASP), and $\mathrm{pH}$ measured in three national nature reserves of China: Changbaishan (CBS), Baotianman (BTM), and Dinghushan (DHS).

\begin{tabular}{lllllll}
\hline & SM $(\%)$ & SOC $\left(\mathrm{g} \mathrm{Kg}^{-1}\right)$ & TSN $\left(\mathrm{g} \mathrm{Kg}^{-1}\right)$ & TSP $\left(\mathrm{g} \mathrm{Kg}^{-1}\right)$ & $\mathrm{ASP}\left(\mathrm{mg} \mathrm{Kg}^{-1}\right)$ & $\mathrm{pH}$ \\
\hline CBS & $61.03 \pm 0.05 \mathrm{a}$ & $81.48 \pm 2.41 \mathrm{a}$ & $6.97 \pm 0.57 \mathrm{a}$ & $0.99 \pm 0.08 \mathrm{a}$ & $1.03 \pm 0.22 \mathrm{~b}$ & $5.10 \pm 0.09 \mathrm{a}$ \\
BTM & $42.51 \pm 0.02 \mathrm{~b}$ & $35.98 \pm 3.24 \mathrm{~b}$ & $3.26 \pm 0.28 \mathrm{~b}$ & $0.17 \pm 0.004 \mathrm{~b}$ & $2.80 \pm 0.54 \mathrm{a}$ & $4.98 \pm 0.06 \mathrm{a}$ \\
DHS & $34.56 \pm 0.01 \mathrm{~b}$ & $25.95 \pm 3.75 \mathrm{c}$ & $2.18 \pm 0.15 \mathrm{~b}$ & $0.22 \pm 0.01 \mathrm{~b}$ & $1.02 \pm 0.25 \mathrm{~b}$ & $3.74 \pm 0.04 \mathrm{~b}$ \\
\hline
\end{tabular}

Data are means \pm standard error $(n=4)$. Different letters indicate significant differences among the three forests $(P=0.05)$ for mean values of each variable.

Table 2 Plant community information in Changbaishan (CBS), Baotianman (BTM) and Dinghushan (DHS).

\begin{tabular}{llll}
\hline Site & Forest type & Forest age (year) & Dominant species \\
\hline CBS & Temperate deciduous and Korean pine forest & 300 & Acer mono, Acer pseudo, Pinus koraiensis, Philadel- \\
& & & $\begin{array}{l}\text { phus schrenkii, Acanthopanax senticosus, Corylus } \\
\text { mandshurica. }\end{array}$
\end{tabular}

BTM Warm-temperate deciduous broad-leaved Forest $\quad 45$

Quercus aliena, Dendrobenthamia japonica, Acer davidii, Viburnum dilatatum, Cerasus tomentosa, Lauraceae obtusiloba.

DHS Subtropical evergreen broad-leaved forest 160

Cryptocarya concinna, Brassaiopsis glomerulata, Castanopsis fissa, Ixora chinensis, 
metabolic rates of soil nematodes derived from scaling relationships of body mass and soil temperature. The following linear model was used:

$$
\ln I=23.055335+0.695071 \times \ln M-0.68642 \times \frac{1}{k T},
$$

where $I$ is the metabolic rate, $M$ is the fresh body mass, $k$ is the Boltzmann constant, and $T$ is the temperature in Kelvin (Schwarz et al., 2017). This yielded metabolic rates expressed in $\mathrm{J} \mathrm{h}^{-1}$. Then, we calculated the energy flux of each nematode trophic group based on the taxon-specific assimilation efficiencies and the summed metabolic rates of all individuals within the corresponding trophic group (Ehnes et al., 2011; Barnes et al., 2014; Schwarz et al., 2017; Shao et al., 2019). We calculated the energy flux to each feeding guild in the food web as $F=\frac{1}{e} \times(X+L)$, where $F$ is the total flux of energy into the feeding guild, $e$ is the specific assimilation efficiency (Schwarz et al., 2017), $X$ is the summed metabolic rates of all individuals within the feeding guild, and $L$ is the energy loss to predation (Barnes et al., 2014). Energy fluxes were expressed as $\mathrm{g} \mathrm{C} \mathrm{m}^{-2} \mathrm{~d}^{-1}$. Richness index (SR) as an indicator of nematode diversity at the community level and it was calculated as $\mathrm{SR}=(S-1) / \log _{\mathrm{e}} N$, where $S$ is the number of taxa identified, and $N$ is the number of individuals identified (Yeates and Bongers, 1999). In addition, we defined the nematode diversity in different trophic groups as the number of genera in each trophic group.

\subsection{Statistical analyses}

Two-way analysis of variance was employed to compare the effect of litter reduction, tree root removal, and their interaction on the energy flux of nematodes, the richness index, the density, and the relative energy flux of nematodes in each forest, which was performed using SPSS version 23.0 (SPSS Inc., Chicago, Illinois, USA). Levene's test was performed to test for homogeneity of variance. Least-significant difference's significant difference tests were used to compare differences among treatments for each sampling event when interactions between litter reduction and tree root removal were significant. Statistical significance was determined at $P<0.05$. Relationships between the energy flux and nematode diversity of different trophic groups were analyzed using regression wizard analyses in SigmaPlot 10.0. Models with the highest coefficient of determination $\left(R^{2}\right)$ were chosen as the best-fit models (Aho et al., 2014).

\section{Results}

\subsection{Nematode energy flux}

Litter reduction did not alter the nematode energy fluxes at high latitudes; however, it reduced the energy fluxes of bacterial-feeding nematodes $(P=0.038$, Fig. $1 \mathrm{G})$ at $\mathrm{mid}$ latitudes and the energy fluxes of plant-feeding nematodes $(P$ $=0.006$, Fig. $1 \mathrm{~K})$, bacterial-feeding nematodes $(P=0.049$, Fig. 1L) and omnivorous-predatory nematodes $(P=0.038$, Fig. $1 \mathrm{~N})$ at low latitudes, thus reducing the energy fluxes of total nematodes in mid- $(P=0.043$, Fig. $1 \mathrm{~J})$ and low-latitude $(P$ $=0.011$, Fig. 10) forests. By contrast, root removal only reduced the energy fluxes of plant-feeding nematodes in high$(P=0.01$, Fig. $1 \mathrm{~A})$ and low-latitude $(P=0.009$, Fig. $1 \mathrm{~K})$ forests, but it did not alter the nematode energy fluxes at mid latitudes. Interestingly, there was no statistical interaction between litter reduction and root removal on nematode energy fluxes (Fig. 1).

\subsection{Nematode abundance and diversity}

Litter reduction at high $(P=0.04$, Fig. $2 \mathrm{~A})$ and mid latitudes $(P$ $=0.001$, Fig. $2 \mathrm{~B})$ and root removal at low latitudes $(P=0.042$, Fig. $2 C)$ reduced soil nematode richness, but these treatments did not alter the density of nematodes (Fig. 2D-2F). Also, there was no statistical interaction between litter reduction and root removal on the density of nematodes and nematode richness index (Fig. 2).

3.3 The relative contributions of each tropic group to total nematode energy flux

Root removal reduced the relative energy flux of plant-feeding nematodes in high- $(P=0.002$; Table 3$)$ and low-latitude $(P=$ 0.009; Table 3) forests (Fig. 3). Besides, root removal increased the relative energy flux of bacterial-feeding nematodes $(P=0.008$; Table 3$)$ in high-latitude forests, and reduced the relative energy flux of fungal-feeding nematodes in midlatitude forests $(P=0.006$, Table 3$)$ (Fig. 3). Litter reduction increased the relative energy flux of fungal-feeding nematodes $(P=0.007$, Table 3$)$ and litter reduction and root removal had a significant interactive effect on the relative energy flux of fungal-feeding nematodes $(P=0.024$, Table 3 ) in mid-latitude forests (Fig. 3).

3.4 Relationships between the energy flux and nematode diversity in different trophic groups

In most cases, nematode diversity in different trophic groups increased with increasing energy flux in nematodes with the exception of fungal-feeding nematodes in all forests (Fig. 4). Specifically, the energy flux of plant-feeding nematodes increased with an increasing number of genera in plantfeeding nematodes $\left(R^{2}=0.7881, P=0.0003\right.$, Fig. 4A; $R^{2}=$ $0.5864, P=0.017$, Fig. $4 \mathrm{E} ; R^{2}=0.7635, P=0.0015$, Fig. $4 \mathrm{I}$ ), the energy flux of bacterial-feeding nematodes increased with an increasing number of genera in bacterial-feeding nematodes $\left(R^{2}=0.6301, P=0.0118\right.$, Fig. $4 \mathrm{~B} ; R^{2}=0.6738, P=$ 0.0059 , Fig. 4F; $R^{2}=0.7006, P=0.0036$, Fig. $4 \mathrm{~J}$ ), and the energy flux of omnivorous-predatory nematodes increased with an increasing number of genera in omnivorous-predatory 

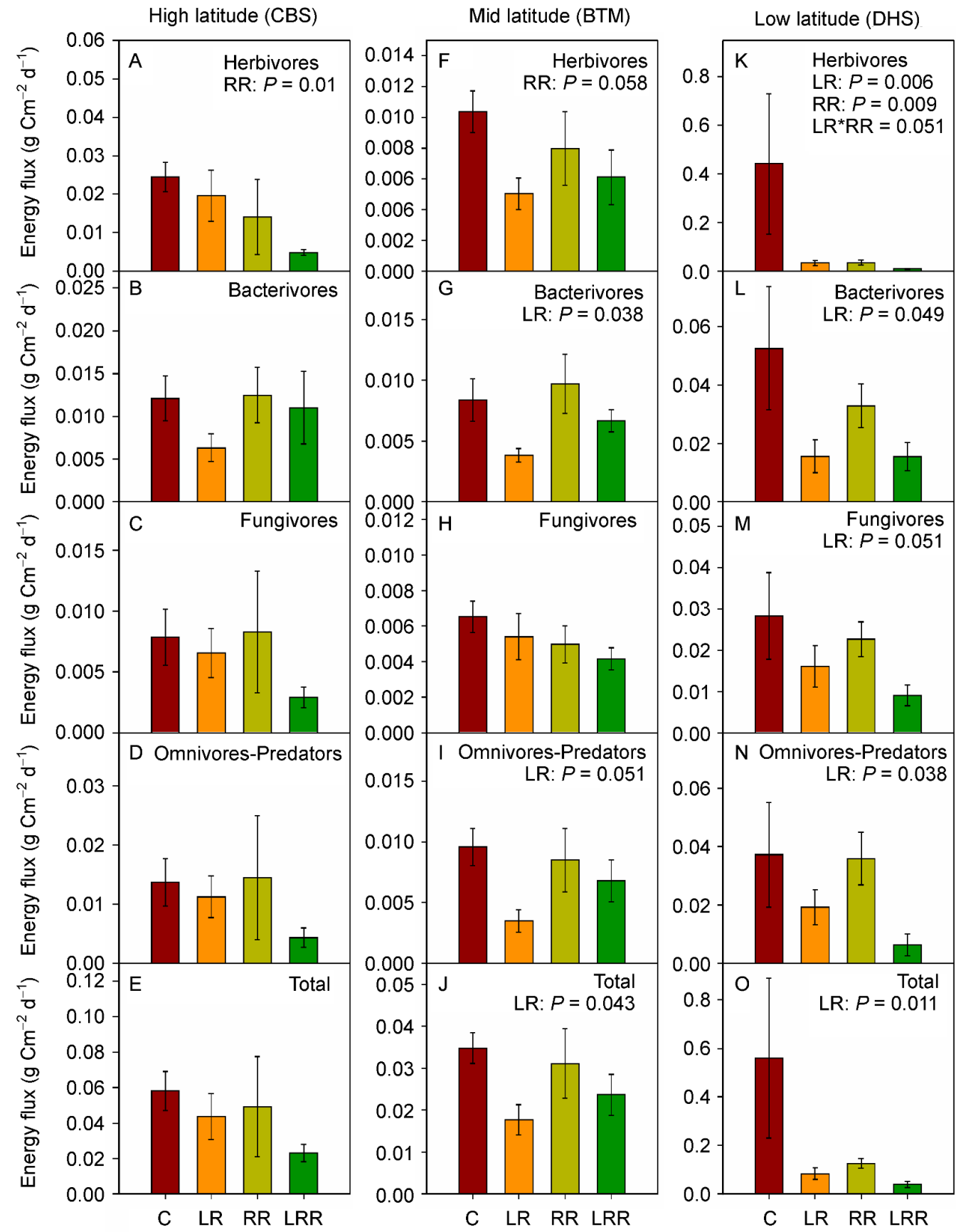

Fig. 1 The energy flux of plant-feeding nematodes (A, F, K), bacterial-feeding nematodes $(B, G, L)$, fungal-feeding nematodes (C, $H, M)$, omnivorous-predatory nematodes $(D, I, N)$, and total nematodes $(E, J, O)$ in control $(C)$, litter reduction (LR), root removal (RR), litter reduction plus root removal (LRR) treatments in the high-latitude Changbaishan (CBS), mid-latitude Baotianman (BTM), and low-latitude Dinghushan (DHS) forests of China. Data are means \pm standard error $(n=4)$. Significant $(P<0.05)$ treatment effects or non-significant trends $(0.05<P<0.1)$ from the two-way analysis of variance are provided in each subpanel.

nematodes $\left(R^{2}=0.6267, P=0.0094\right.$, Fig. $4 \mathrm{D} ; R^{2}=0.7195, P$ $=0.0017$, Fig. $4 \mathrm{H} ; R^{2}=0.6703, P=0.0045$, Fig. $4 \mathrm{~L}$ ) in high, mid, and low latitude forests.

\section{Discussion}

In the present study, litter reduction at high and mid latitudes and root removal at low latitudes reduced nematode richness 


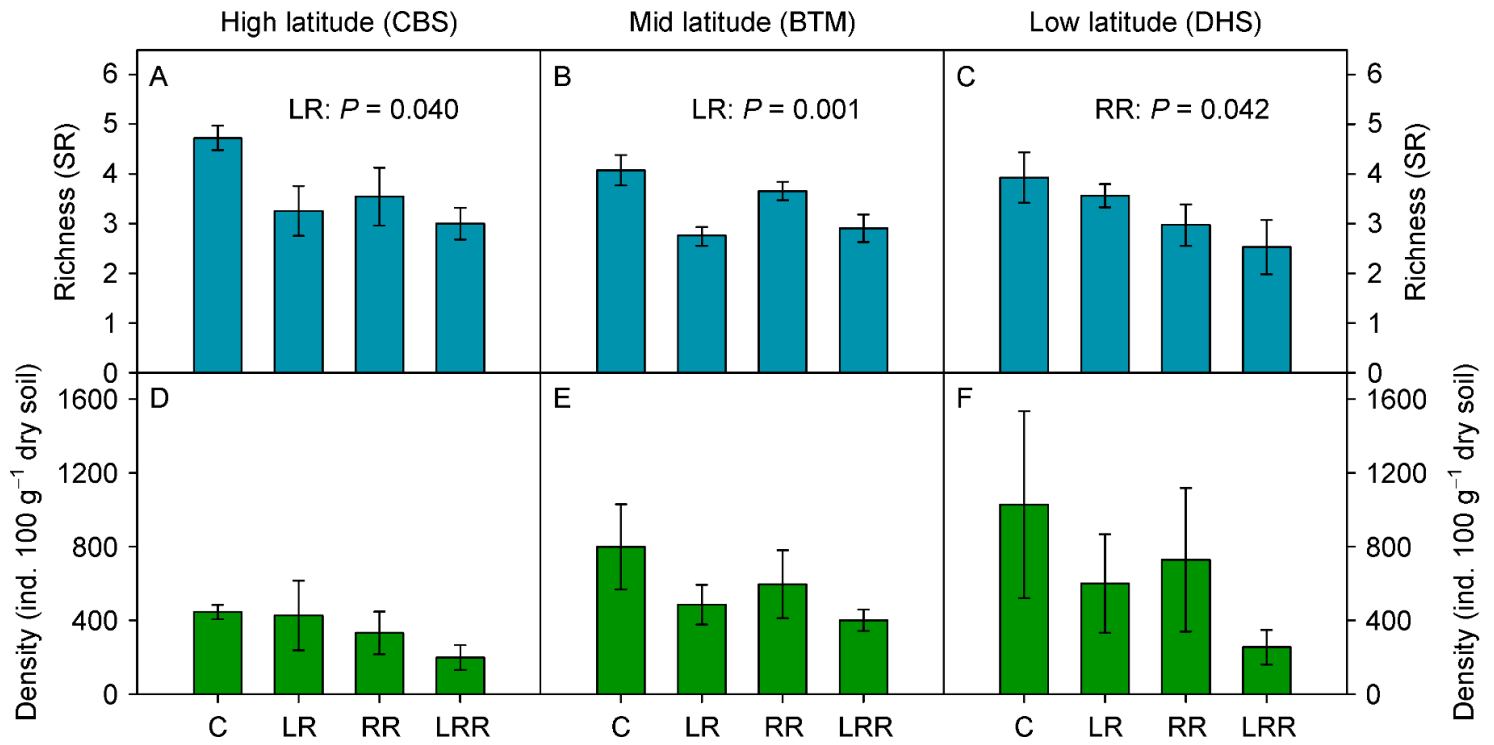

Fig. 2 Richness index (SR) and density of nematodes under control (C), litter reduction (LR), root removal (RR), and litter reduction + root removal (LRR) in three forests in China at different latitudes: Changbaishan (CBS), Baotianman (BTM), and Dinghushan (DHS). (A) Nematode richness index at high-latitude forests. (B) Nematode richness index at mid-latitude forests. (C) Nematode richness index at lowlatitude forests. (D) Density of nematodes at high-latitude forests. (E) Density of nematodes at mid-latitude forests. (F) Density of nematodes at low-latitude forests. Significant $(P<0.05)$ treatment effects from the two-way analysis of variance are provided in each subpanel.

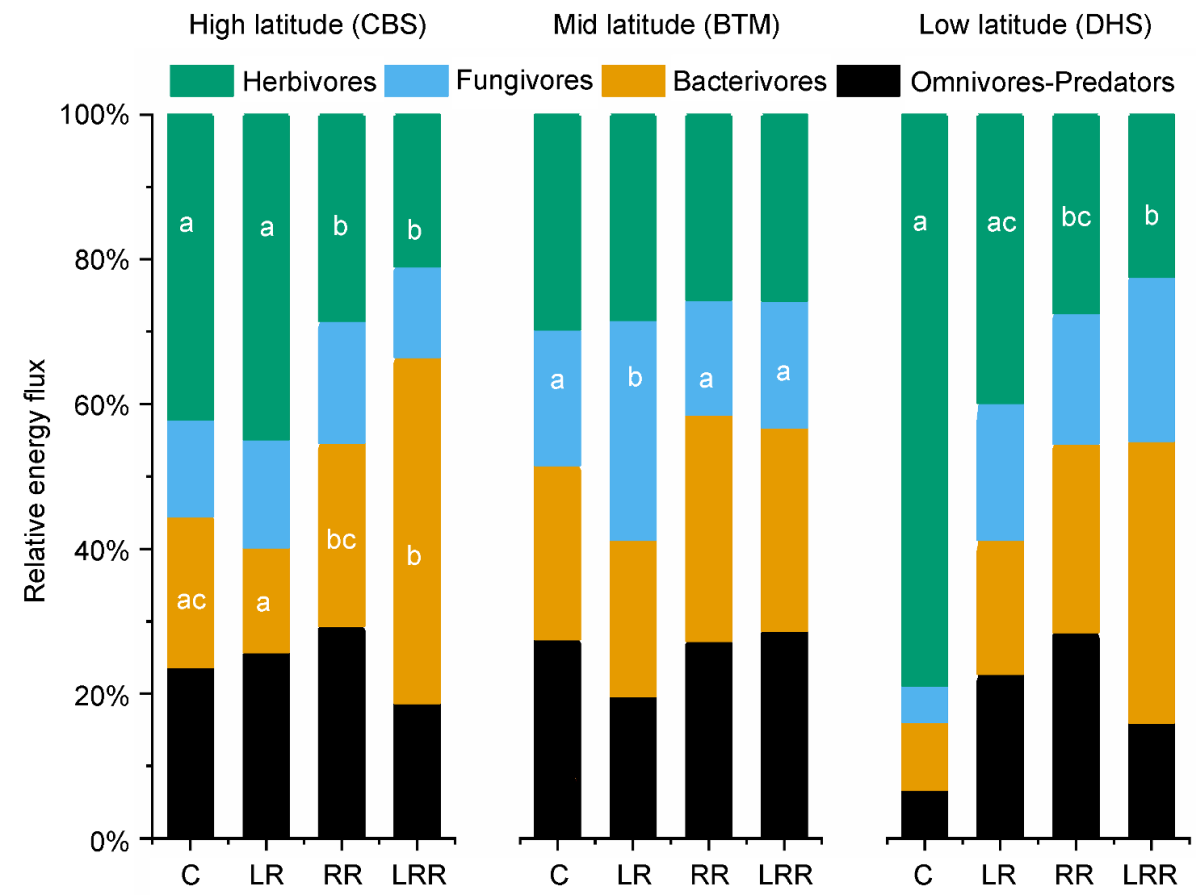

Fig. 3 The relative contributions of each tropic group to total nematode energy flux in control (C), litter reduction (LR), root removal (RR), and litter reduction plus root removal (LRR) treatments in high-latitude Changbaishan (CBS), mid-latitude Baotianman (BTM), and lowlatitude Dinghushan (DHS) field experiments $(n=4)$ in forests in China. Different lowercase letters represent significant differences $(P<0.1)$. Herbivores: plant-feeding nematodes; Fungivores: fungal-feeding nematodes; Bacterivores: bacterial-feeding nematodes; OmnivoresPredators: omnivorous-predatory nematodes.

but did not alter nematode abundance. These findings do not support our hypothesis that litter reduction and/or root removal will decrease the abundance of soil nematodes; however, these results support our main hypothesis that litter reduction and/or root removal will decrease the diversity of soil nematodes and that the effects on nematode diversity are 
Table 3 Results ( $P$ values) of two-way analysis of variance on the effects of litter reduction (LR), root removal (RR), and their interactions on relative contributions of each tropic group to total nematode energy flux.

\begin{tabular}{|c|c|c|c|c|c|c|c|c|c|c|c|c|}
\hline & \multicolumn{4}{|l|}{ CBS } & \multicolumn{4}{|l|}{ BTM } & \multicolumn{4}{|l|}{ DHS } \\
\hline & $\mathrm{H}$ & $\mathrm{Ba}$ & $\mathrm{Fu}$ & Om-pr & $\mathrm{H}$ & $\mathrm{Ba}$ & $\mathrm{Fu}$ & Om- pr & $\mathrm{H}$ & $\mathrm{Ba}$ & $\mathrm{Fu}$ & Om-pr \\
\hline LR & 0.78 & 0.96 & 0.76 & 0.81 & 0.64 & 0.82 & 0.007 & 0.14 & 0.26 & 0.41 & 0.14 & 0.97 \\
\hline$R R$ & 0.002 & 0.008 & 0.732 & 0.713 & 0.10 & 0.061 & 0.006 & 0.17 & 0.009 & 0.052 & 0.20 & 0.36 \\
\hline $\mathrm{LR}^{*} \mathrm{RR}$ & 0.91 & 0.42 & 0.27 & 0.57 & 0.96 & 0.94 & 0.024 & 0.074 & 0.63 & 0.87 & 0.70 & 0.063 \\
\hline
\end{tabular}

Italicized values indicate significant effects $(P<0.05)$. H: plant-feeding nematodes; Ba: bacterial-feeding nematodes; Fu: fungal-feeding nematodes; Om-pr: omnivorous-predatory nematodes.

affected by climate and plant resource types. Plant and soil organisms are closely linked by indirect and direct pathways (Wardle et al., 2004). Therefore, changes in plant resource inputs are expected to affect soil biological communities (Wardle, 2006). Although the reduction or removal of plant resources reduced the input of plant resources, the changes of nematode diversity may be due to litter reduction and root removal resulted in the decreases of some dominant or rare genera. Since the presence of a large amount of soil organic matter, undecomposed plant roots, and remaining leaf litter, the ecological niche (e.g., space and food resources) of the decreased genera may be occupied by other genera, which may support the abundances of nematodes (Ghilarov, 1977; Kozdrój and van Elsas, 2000; Bardgett et al., 2005). The litter layer plays an important role in maintaining soil microenvironments (such as soil temperature and moisture) at mid and high latitudes because of the relatively slow litter decomposition rate (Meentemeyer, 1978), which may be an important reason for the decrease of nematode diversity as affected by litter reduction at high and mid latitudes. In addition, considering the greater root turnover rate at low latitudes (Gill and Jackson, 2000), root removal may have a greater impact on nematode communities at low latitudes and potentially decrease nematode diversity in low-latitude forests. Notably, different types of diversity indices may assign different weight to dominant and rare taxa (Li et al., 2020).

Interestingly, litter reduction did not alter the nematode energy fluxes at high latitudes. However, litter reduction reduced the energy fluxes of bacterial-feeding nematodes at mid latitudes and the energy fluxes of plant-feeding, bacterialfeeding and omnivorous-predatory nematodes at low latitudes, thus reducing the energy fluxes of total nematodes in mid- and in low-latitude forests, respectively. By contrast, root removal only reduced the energy fluxes of plant-feeding nematodes in high- and low-latitude forests, but it did not alter the nematode energy fluxes at mid latitudes. These findings partially supports our hypothesis that litter reduction and/or root removal will decrease the energy flux of soil nematodes and that the effects on nematode energy fluxes are affected by climate and plant resource types. Previous studies suggested that the litter decomposition rates are faster at mid and low latitudes, relative to high latitudes, due to the higher temperature and humidity at mid and low latitudes
(Meentemeyer, 1978; Guo, 1993; Liu et al., 2006; Butenschoen et al., 2011). As a result, there are faster litter resource inputs in the soil food web at mid and low latitudes. Therefore, the effects of litter reduction on the energy fluxes of soil nematodes were greater in mid- and low-latitude forests than in high-latitude forests. By contrast, root removal only reduced the energy flux of plant-feeding nematodes in highand low-latitude forests. In general, as a representative of low trophic level, plant-feeding nematodes feed on plant roots or root hairs (Ferris and Bongers, 2006; Neher, 2010). Root removal reduced the input of plant roots to a certain extent. Plant-feeding nematodes can only utilize the plant root resources that have not been decomposed in the soil, which could lead to the decrease of the energy flux of plant-feeding nematodes. A previous study in northern temperate forests suggested that soil organisms mainly use root-derived carbon input (Pollierer et al., 2007), which might be a possible explanation that root removal reduced the energy flux of plantfeeding nematodes in high-latitude forests. In addition, considering the greater root turnover rate at low latitudes (Gill and Jackson, 2000), root removal may have a greater impact on nematode communities at low latitudes and potentially decrease nematode energy flux in low latitude forests. There was no significant interactions between litter reduction and root removal on most nematode variables in our experiment, a possible explanation for the lack of these interactions in our study is that most nematode variables were affected by a reduction in their food resources (e.g., rhizodeposits) in the plots where the roots were removal because the presence of undecomposed plant roots can still maintain the physical environment in the soil (e.g., soil porosity), whereas most nematode variables were more likely to be affected by the changes in soil environment in the plots received "litter reduction" treatments because the presence of a large amount of soil organic matter can still provide large amounts of detritus-derived food sources. Therefore, it is difficult for these two different pathways to interact to affect those nematode variables (Chen et al., 2018).

In most cases, nematode diversity in different trophic groups increased with increasing energy flux to nematodes with the exception of fungal-feeding nematodes in all forests. A greater soil biodiversity often reflects higher complexity and stability in the soil food web (Tardy et al., 2014; Shao et al., 

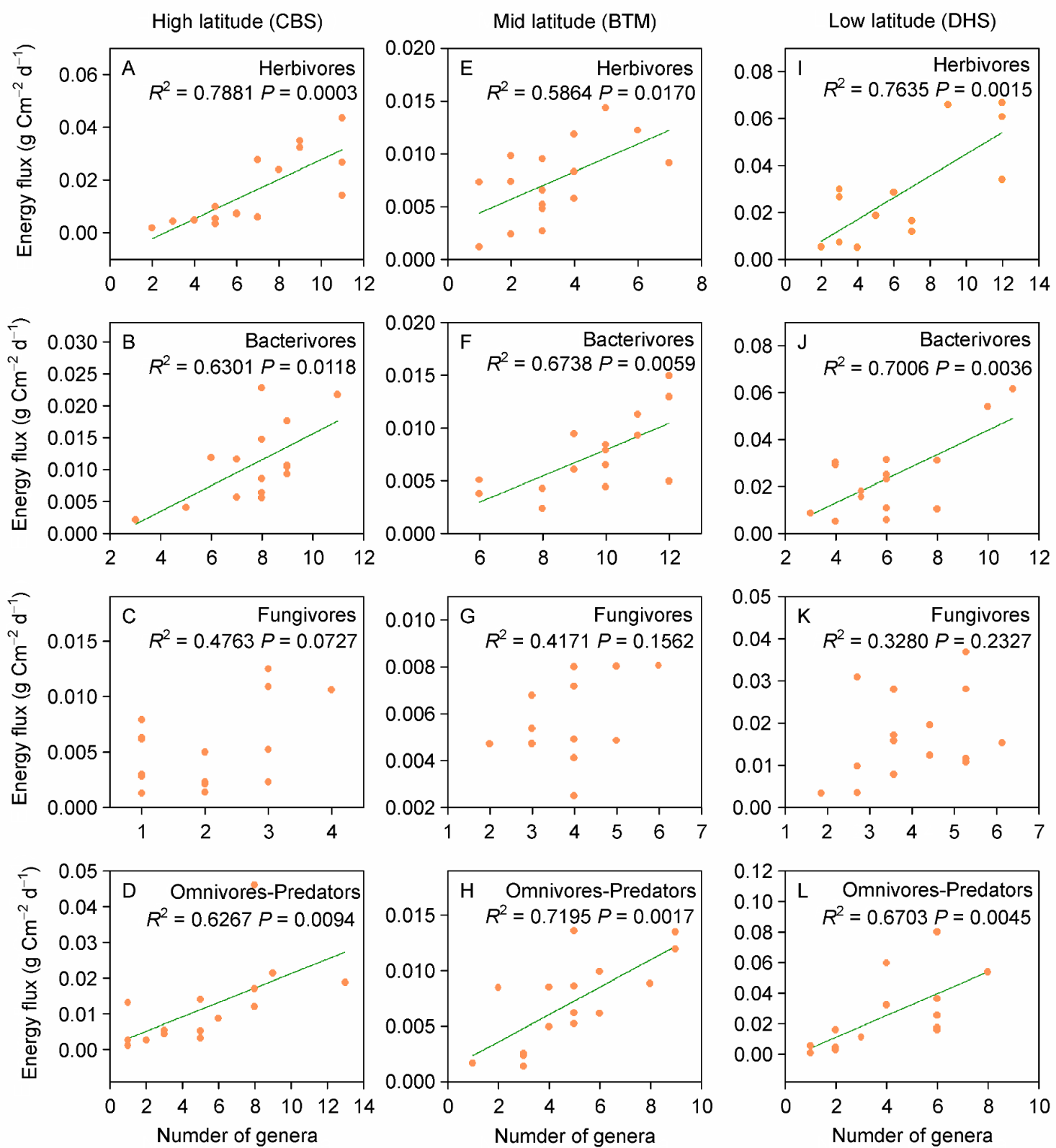

Fig. 4 Relationships between the energy flux and nematode diversity of different trophic groups in high-latitude Changbaishan (CBS), midlatitude Baotianman (BTM), and low-latitude Dinghushan (DHS) forests in China. (A, E, I) Relationship between the energy flux of plantfeeding nematodes and the number of genera of plant-feeding nematodes. (B, F, J) Relationship between the energy flux of bacterial-feeding nematodes and the number of genera of bacterial-feeding nematodes. (C, G, K) Relationship between the energy flux of fungal-feeding nematodes and the number of genera of fungal-feeding nematodes. (D, H, L) Relationship between the energy flux of omnivorous-predatory nematodes and the number of genera of omnivorous-predatory nematodes.

2016). However, many studies on soil food webs suggest that a relatively slower energy channel can imply higher stability (De Ruiter et al., 1995; Moore et al., 1996; McCann et al., 1998; Rooney et al., 2006; Rooney and McCann, 2012). Therefore, soil biodiversity is closely related to the rates of energy flow in soil food webs (Shao et al., 2019). However, little is known about the relationship between diversity and energy flux, which limits our understanding of regulating factors in soil food web stability and plant-soil feedback. Perhaps, exploring the energy fluxes through soil food webs can help generate a better mechanistic understanding of the regulating forces of soil biodiversity. One limitation of this study is that we only selected a single population in the soil food webs, and this does not fully reflect the relationship 
between real diversity and energy flow dynamics. In addition, we speculate that the relationship between diversity and energy flux may not be a simple linear relationship, which is worthy of further study. Although there was a positive correlation between nematode energy fluxes and nematode diversity across the three forests, we noted that the nematode energy fluxes were much greater at low latitudes than at high and mid latitudes, but nematode diversity did not show such a clear trend. So it is possible that diversity declined more rapidly at high latitudes if the energy flux decreases at the same rate in different forests due to some disturbances, such as changes in land use patterns caused by human activities or ecological invasions. Furthermore, global warming may lead to faster rates of nematode energy flow and an increase in their diversity at higher latitudes because global warming may make nematodes experience temperatures much closer to their physiological optimum than those nematodes at low latitudes. Nevertheless, the present study explored the effects of aboveground plants on underground soil organisms from the perspective of energy flow dynamics, which provided novel information on plant-soil interactions and future research directions.

\section{Acknowledgments}

This study was sponsored by the National Natural Science Foundation of China (31971534) and the Innovation Scientists and Technicians Troop Construction Projects of Henan Province. We thank LetPub (www.letpub.com) for its linguistic assistance during the preparation of this manuscript. We are also very grateful for the support from the forest sites.

\section{Conflicts of interest}

The authors declare that they have no conflict of interest. All authors have seen and agreed to the submitted version of the manuscript.

\section{References}

Aho, K., Derryberry, D., Peterson, T., 2014. Model selection for ecologists: the worldviews of AIC and BIC. Ecology 95, 631-636.

Bardgett, R.D., van der Putten, W.H., 2014. Belowground biodiversity and ecosystem functioning. Nature 515, 505-511.

Bardgett, R.D., Wardle, D.A., 2010. Aboveground-belowground linkages. Oxford University Press.

Bardgett, R.D., Yeates, G.W., Anderson, J.M., 2005. Patterns and Determinants of Soil Biological Diversity. In: Bardgett, R., Usher, M., Hopkins, D., eds. Biological Diversity and Function in Soils. Cambridge University Press, Cambridge, pp. 100-118.

Barker, K.R., 1985. Nematode extraction and bioassays. An Advanced Treatise on Meloidogyne 2, 19-35.

Barnes, A.D., Jochum, M., Mumme, S., Haneda, N.F., Farajallah, A., Widarto, T.H., Brose, U., 2014. Consequences of tropical land use for multitrophic biodiversity and ecosystem functioning. Nature Communications 5, 5351.
Bongers, T., Ferris, H., 1999. Nematode community structure as a bioindicator in environmental monitoring. Trends in Ecology \& Evolution 14, 224-228.

Bowden, R.D., Nadelhoffer, K.J., Boone, R.D., Melillo, J., Garrison, J. B., 1993. Contributions of aboveground litter, belowground litter, and root respiration to total soil respiration in a temperate mixed hardwood forest. Canadian Journal of Forest Research 23, 1402 1407.

Butenschoen, O., Scheu, S., Eisenhauer, N., 2011. Interactive effects of warming, soil humidity and plant diversity on litter decomposition and microbial activity. Soil Biology \& Biochemistry 43, 19021907.

Chen, D.M., Xing, W., Lan, Z.C., Saleem, M., Wu, Y.Q.Q.G., Hu, S.J., Bai, Y.F., 2018. Direct and indirect effects of nitrogen enrichment on soil organisms and carbon and nitrogen mineralization in a semi-arid grassland. Functional Ecology 33, 175-187.

Coleman, D.C., Crossley, D.A. Jr, Hendrix, P.F., 2004. Primary production processes in soils: roots and rhizosphere associates. In: Coleman, D.C., Crossley, D.A., Hendrix, P.F., eds. Fundamentals of Soil Ecology (Second Edition). Academic Press Burlington, pp. 23-46.

Colloff, M., 2004. Book review: communities and ecosystems: linking the above-ground and below-ground components. Austral Ecology 29, 358-359.

De Ruiter, P.C., Neutel, A.M., Moore, J.C., 1995. Energetics, patterns of interaction strengths, and stability in real ecosystems. Science 269, 1257-1260.

Ehnes, R.B., Rall, B.C., Brose, U., 2011. Phylogenetic grouping, curvature and metabolic scaling in terrestrial invertebrates. Ecology Letters 14, 993-1000.

Elfstrand, S., Lagerlöf, J., Hedlund, K., Mårtensson, A., 2008. Carbon routes from decomposing plant residues and living roots into soil food webs assessed with $13 \mathrm{C}$ labelling. Soil Biology \& Biochemistry $40,2530-2539$.

Ferris, H., Bongers, T., 2006. Nematode Indicators of organic enrichment. Journal of Nematology 38, 3-12.

Freckman, D.W., 1988. Bacterivorous nematodes and organic-matter decomposition. Agriculture, Ecosystems \& Environment 24, 195 217.

Ghilarov, M.S., 1977. Why so many species and so many individuals can coexist in the soil. Ecological Bulletins 25, 593-597.

Gill, R.A., Jackson, R.B., 2000. Global patterns of root turnover for terrestrial ecosystems. New Phytologist 147, 13-31.

Guo, J.X., 1993. Study on litter decomposition in Leymus chinensis grassland-Relation of litter decomposition to ecological environment. Acta Ecologica Sinica, 13, 214-250

Högberg, P., Nordgren, A., Buchmann, N., Taylor, A.F.S., Ekblad, A., Högberg, M.N., Nyberg, G., Ottosson-Löfvenius, M., Read, D.J., 2001. Large-scale forest girdling shows that current photosynthesis drives soil respiration. Nature 411, 789-792.

Holtkamp, R., Kardol, P., van der Wal, A., Dekker, S.C., van der Putten, W.H., de Ruiter, P.C., 2008. Soil food web structure during ecosystem development after land abandonment. Applied Soil Ecology 39, 23-34.

Hugot, J.P., Baujard, P., Morand, S., 2001. Biodiversity in helminths and nematodes as a field of study: an overview. Nematology 3 , 
199-208.

Kozdrój, J., van Elsas, J.D., 2000. Response of the bacterial community to root exudates in soil polluted with heavy metals assessed by molecular and cultural approaches. Soil Biology \& Biochemistry 32, 1405-1417.

Li, J.N., Peng, P.Q., Zhao, J., 2020. Assessment of soil nematode diversity based on different taxonomic levels and functional groups. Soil Ecology Letters 2, 33-39.

Liu, Q., Peng, S.L., Bi, H., Zhang, H.Y., Li, Z.A., Ma, W.H., Li, N.Y., 2006. Nutrient dynamics of foliar litter in reciprocal decomposition in tropical and subtropical forests. Frontiers of Forestry in China 1 243-252.

Lu, H.B., Liu, S.R., Wang, H., Luan, J.W., Schindlbacher, A., Liu, Y.C., Wang, Y., 2017. Experimental throughfall reduction barely affects soil carbon dynamics in a warm-temperate oak forest, central China. Scientific Reports 7, 15099.

McCann, K., Hastings, A., Huxel, G.R., 1998. Weak trophic interactions and the balance of nature. Nature 395, 794-798.

Meentemeyer, V., 1978. Macroclimate and lignin control of litter decomposition rates. Ecology 59, 465-472.

Moore, J.C., de Ruiter, P.C., Hunt, H.W., Coleman, D.C., Freckman, D. W., 1996. Microcosms and soil ecology: critical linkages between fields studies and modelling food webs. Ecology 77, 694-705.

Nadelhoffer, K.J., Boone, R.D., Bowden, R.D., Canary, J.D., Kaye, J., Micks, P., Ricca, A., Aitkenhead-Peterson, J.A., Lajtha, K., McDowell, W.H., 2004. The DIRT Experiment: litter and Root Influences on Forest Soil Organic Matter Stocks and Function. In Foster, D., Aber, J., eds. Forest Landscape Dynamics in New England: Ecosystems Structure and Function as a Consequence of 5000 years of Change. Oxford: Oxford University Press.

Neher, D.A., 2001. Role of nematodes in soil health and their use as indicators. Journal of Nematology 33, 161-168.

Neher, D.A., 2010. Ecology of plant and free-Living nematodes in natural and agricultural soil. Annual Review of Phytopathology 48 , 371-394.

Pausch, J., Hofmann, S., Scharroba, A., Kuzyakov, Y., Ruess, L., 2016. Fluxes of root-derived carbon into the nematode micro-food web of an arable soil. Food Webs 9, 32-38.

Pollierer, M.M., Reinhard, L., Körner, C., Maraun, M., Scheu, S., 2007. The underestimated importance of belowground carbon input for forest soil animal food webs. Ecology Letters 10, 729-736.

Qu, L.R., Wang, C., Bai, E., 2020. Evaluation of the ${ }^{18} \mathrm{O}-\mathrm{H}_{2} \mathrm{O}$ incubation method for measurement of soil microbial carbon use efficiency. Soil Biology \& Biochemistry 145, 107802.

Rooney, N., McCann, K., Gellner, G., Moore, J.C., 2006. Structural asymmetry and the stability of diverse food webs. Nature 442 265-269.

Rooney, N., McCann, K.S., 2012. Integrating food web diversity, structure and stability. Trends in Ecology \& Evolution 27, 40-46.

Scheunemann, N., Maraun, M., Scheu, S., Butenschoen, O., 2015. The role of shoot residues vs. crop species for soil arthropod diversity and abundance of arable systems. Soil Biology \& Biochemistry 81, 81-88.

Schwarz, B., Barnes, A.D., Thakur, M.P., Brose, U., Ciobanu, M., Reich, P.B., Rich, R.L., Rosenbaum, B., Stefanski, A., Eisenhauer, N., 2017. Warming alters energetic structure and function but not resilience of soil food webs. Nature Climate Change 7, 895-900. Shao, Y.H., Wang, X.L., Zhao, J., Wu, J.P., Zhang, W.X., Neher, D.A., Li, Y.X., Lou, Y.P., Fu, S.L., Kardol, P., 2016. Subordinate plants sustain the complexity and stability of soil micro-food webs in natural bamboo forest ecosystems. Journal of Applied Ecology 53, 130-139.

Shao, Y.H., Zhang, W.X., Eisenhauer, N., Liu, T., Ferlian, O., Wang, X. L., Xiong, Y.M., Liang, C.F., Fu, S.L., 2019. Exotic earthworms maintain soil biodiversity by altering bottom-up effects of plants on the composition of soil microbial groups and nematode communities. Biology and Fertility of Soils 55, 213-227.

Soil Survey Staff, 1999. Soil Taxonomy. A Basic System of Soil Classification for Making and Interpreting Soil Surveys. USDA Agriculture Handbook No. 436. U.S. Government Print Office, Washington DC.

Tardy, V., Mathieu, O., Lévêque, J., Terrat, S., Chabbi, A., Lemanceau, P., Ranjard, L., Maron, P.A., 2014. Stability of soil microbial structure and activity depends on microbial diversity. Environmental Microbiology Reports 6, 173-183.

van den Hoogen, J., Geisen, S., Routh, D., Ferris, H., Traunspurger, W., Wardle, D.A., de Goede, R.G.M., Adams, B.J., Ahmad, W., Andriuzzi, W.S., Bardgett, R.D., Bonkowski, M., Campos-Herrera, R., Cares, J.E., Caruso, T., de Brito Caixeta, L., Chen, X., Costa, S. R., Creamer, R., Mauro da Cunha Castro, J., Dam, M., Djigal, D., Escuer, M., Griffiths, B.S., Gutiérrez, C., Hohberg, K., Kalinkina, D., Kardol, P., Kergunteuil, A., Korthals, G., Krashevska, V., Kudrin, A.A., Li, Q., Liang, W., Magilton, M., Marais, M., Martín, J. A.R., Matveeva, E., Mayad, E.H., Mulder, C., Mullin, P., Neilson, R., Nguyen, T.A.D., Nielsen, U.N., Okada, H., Rius, J.E.P., Pan, K., Peneva, V., Pellissier, L., Carlos Pereira da Silva, J., Pitteloud, C., Powers, T.O., Powers, K., Quist, C.W., Rasmann, S., Moreno, S. S., Scheu, S., Setälä, H., Sushchuk, A., Tiunov, A.V., Trap, J., van der Putten, W., Vestergård, M., Villenave, C., Waeyenberge, L., Wall, D.H., Wilschut, R., Wright, D.G., Yang, J.I., Crowther, T.W., 2019. Soil nematode abundance and functional group composition at a global scale. Nature 572, 194-198.

Wardle, D.A., 2005. How Plant Communities Influence Decomposer Communities. In: Bardgett, R.D., Usher, M.B., Hopkins, D.W., eds. Biological Diversity and Function in Soils. Cambridge University Press Cambridge, pp. 119-138.

Wardle, D.A., 2006. The influence of biotic interactions on soil biodiversity. Ecology Letters 9, 870-886.

Wardle, D.A., 2010. Communities and ecosystems: Linking the above-ground and below-ground components. Austral Ecology 29, 358-359.

Wardle, D.A., Bardgett, R.D., Klironomos, J.N., Setälä, H., van der Putten, W.H., Wall, D.H., 2004. Ecological linkages between aboveground and belowground biota. Science 304, 1629-1633.

Wilschut, R.A., Geisen, S., 2020. Nematodes as drivers of plant performance in natural systems. Trends in Plant Science, 26, 237247.

Yeates, G.W., 1979. Soil nematodes in terrestrial ecosystems. Journal of Nematology 11, 213-229.

Yeates, G.W., Bongers, T., 1999. Nematode diversity in agroecosystems. Agriculture, Ecosystems \& Environment 74, 113-135.

Yeates, G.W., Bongers, T., De Goede, R.G.M., Freckman, D.W., 
Georgieva, S.S., 1993. Feeding habits in soil nematode families and genera-an outline for soil ecologists. Journal of Nematology 25, 315-331.

Yu, S.Q., Chen, Y.Q., Zhao, J., Fu, S.L., Li, Z.A., Xia, H.P., Zhou, L.X., 2017. Temperature sensitivity of total soil respiration and its heterotrophic and autotrophic components in six vegetation types of subtropical China. Science of the Total Environment 607-608, 160-167.
Zhang, Q., 2011. Dinghushan National Field Research Station of Forest Ecosystem (1998-2008). In: Sun, H.L., Yu, G.R., Ouyang, Z., He, H.L., eds. Chinese Ecosystem Research Network Dataset. Forest Ecosystems.

Zhao, J., Xiao, J., Zhang, W., Fu, Z.Y., Zhang, M.Y., Liu, T., Tan, Q.J., Wang, K.L., 2019. A method for estimating nematode body lengths for use in the calculation of biomass via a simplified formula. Soil Biology \& Biochemistry 134, 36-41. 